\title{
Connecting to the past: Newspaper digitization in the Nordic countries
}

\begin{abstract}
Majlis Bremer-Laamanen
is Head of the Centre for Microfilming and Conservation at Helsinki University Library - National Library of Finland. The centre is also responsible for the Library's digitization activities. Majlis Bremer-Laamanen is responsible for the coordination of the national digitization cooperation (eKAM) of Finnish memory institutions, with the goal of enhancing digitization policy and program. The centre is also coordinating The Finnish Digitisation Programme for University, Scientific and Public Libraries and is a member of the Mikkeli University Consortium. Majlis Bremer-Laamanen has participated in various projects relating to microfilming and digitization, among others as a project leader for the Nordic TIDEN — Digitization of Historical Newspapers-project 1998-2001. She has been secretary for the Preservation and Conservation Section of the International Federation of Library Associations and Institutions and is a member of the IFLA Newspapers Section and has been Work Package Leader in the Minerva Project, funded from the Information Society Technologies Programme of the European Union.
\end{abstract}

Keywords: digitization, microfilming, newspapers, cultural heritage

Abstract Digital newspaper projects are a hot topic around the world. One pioneer in the field of digitizing newspapers is the Nordic TIDEN project, launched in 2001. Today the amount of online pages has risen from 400,000 at launch to 1.6 million. In Finland and Sweden, full text search is available. The Historical Newspaper Library in Finland is highly regarded among researchers and the public. It is easy to use in its Google-like approach. The users are connected to places, questions, nations and human life over centuries. The process of digitizing newspapers includes microfilming, digitization and optical character recognition, identification and database import. The speed and automation of the production environment is essential. The automated processes of today offer the coordinates to each word in the paper and the users get better service as the words are highlighted. Images are of a better quality as grayscale images can be handled automatically. In digital futures, the digital collection management will be an exciting challenge. The infrastructure is changing fast as well as the expectations. We have to improve access in various ways, including automatic translation to old holdings and meeting places for users: connecting them to each other and to holdings in other heritage sectors. Newspaper collections are targets that have a great demand on the internet from researchers as well as the public at large. Our digitized historical newspaper collections and the born digital ones are connecting the users to places, questions, nations and human life over centuries. Incidents from the past are suddenly easily accessible. The past is living in the present.

Journal of Digital Asset Management (2006) 2, 168-171. doi:10.1057/palgrave.dam.3650027

Majlis Bremer-Laamanen Centre for Microfilming and Conservation, Helsinki University Library - National Library of Finland,

Saimaankatu 6,

FI-50100 Mikkeli,

Finland

Tel: + 358152023420

Fax +358 152023434

E-mail:

majlis.bremer-laamanen@

helsinki.fi

\section{NEWSPAPERS HAVE A HIGH STATUS IN NORDIC COUNTRIES}

Newspapers are perhaps astonishingly still the most important media in Finland.The Norwegian national library says that Norway is the country with the largest newspaper reading population. Newspapers have a very high status in all the Nordic countries.

All over the world, newspapers have adjusted to new sources of media like radio, movies and television. Today they face "ghosts" like the internet. How much will the new internet behavior interfere with the life of today?
Daily paper is a way of life in Finland The average use of newspapers in Finland is almost an hour per person per day and it has not diminished.

The daily paper is a way of life. It is delivered to your front door in the morning, to be enjoyed with a cup of coffee or tea. It gives the reader a moment of peace and comfort together with the national and local news before the day starts. Free newspapers are delivered on the subways and trains on your way to work. 


\section{Media channels for work and leisure}

The appearance of many newspapers has changed to a modern tabloid format, actively reaching out to the customers and the youth at schools, delivering information, science, leisure and advertisements. Surprisingly perhaps, the heavy users of computers are heavy newspaper readers. Over 90 per cent of young Finns read a newspaper each week. ${ }^{2}$

Newspapers are the media channel that is daily best reaching the Finns. Hence, over half of all money spent on advertising is in the newspaper business. It is, for example, the major channel for information on stock exchange today. $^{3}$

Newspapers are the most important research media in Finland. They are the prime source of investigation in more than half of the research projects in Finland and almost in half in Sweden. They are used as source material for research in the fields of media, history, political science, sociology, pedagogy, art, business, natural sciences and technology. ${ }^{4}$

As such, the interest in Finnish historical newspapers is high. Newspapers are the most used individual group of the Finnish national library collection.

\section{The role of online newspapers supportive}

Online newspapers are produced all over the world, also in the Nordic countries. These papers are usually available via the National Libraries. We have about one hundred newspaper titles on the web among the 900 periodicals in Finland.

Surprisingly, the role of the Finnish online paper is to support the paper version. Thus, their monetary importance is still quite low. These papers are improving and the overall development in knowledge society will influence their use. Also look-alike editions of newspapers are available on the web in Finland since 2002.

\section{CONVERTING LARGE VOLUMES TO DIGITAL FORM}

John S. North's description of newspapers is relevant and sheds some light on the reasons for the rather late start for newspaper digitization projects.

"Periodicals bibliography is a much neglected field, for understandable reasons. First, it is massive: periodicals easily outdo monographs in sheer volume of publication. Second, no clear definition of a periodical is generally accepted, and the working definition varies from library to library. Third, any one periodical is likely to change in some of its primary bibliographical elements from issue to issue (title, subtitle, format, editor, publisher, proprietor, frequency, printer, size, etc.). Moreover, periodicals are often considered ephemeral: stale news, cheap popular information, trivial records. In short, throw-aways. They are often poor quality paper, arriving in libraries unbound and in endless irregular succession, so are unwieldy to shelve and catalogue, and are seldom to be found in complete runs, seldom well indexed. They are the nightmares of librarians and bibliographers." (John S. North). ${ }^{6}$

The newspaper holdings have been considered a nightmare for digitization as well. The size of newspapers grew in the late 19 th century to four times the size of a tabloid of today. The poor print, the poor quality paper and the use of Gothic Fraktur and Roman text in the Nordic countries made a challenge for digitization. Even more of a challenge was the optical character recognition (OCR) needed to make the text searchable from the image of the paper.

Digital newspaper projects are a new hot topic in Europe and around the world. The British Library is going to digitize and give free text search to two million pages. Austria and Estonia are well under way with their newspaper projects. The United States (The Library of Congress) is planning newspaper projects and so is the National Library of Australia.

\section{The Nordic Historical Newspaper Project - TIDEN has $\mathbf{1 . 6}$ million online pages}

One pioneer in the field of digitizing newspapers is the Nordic TIDEN project, ${ }^{7}$ which started in 1998 and was launched on the web in 2001.

The libraries participating were the Royal Library of Stockholm in Sweden, the National Library of Norway and the State and University Library of Aarhus in Denmark. The coordinator for the project was Helsinki University Library - National Library of Finland, the Centre for 
Microfilming, Conservation and Digitisation, which is situated in Mikkeli, a smaller town in Eastern Finland.

The aim of the TIDEN-project was:

- to test the criteria for microfilm as a platform for digitization and full text search;

- to build production lines for the digitization of newspapers;

- to integrate the digitization to the libraries ordinary functions and

- to give a continuous widening access to newspapers out of copyright.

Today, the amount of online pages has risen from 400,000 at launch to 1.6 million. In Finland and Sweden full text search is available.

\section{Automation is needed for cost -effectiveness}

When dealing with large collections like newspapers, the production has to be as fully automated as possible. This was one of the aims when TIDEN started. The possibilities to do so are far better today than five years ago. Today, we are changing our half-automated processes to a faster automated process. We are working together with the Royal Library of Sweden to test and enhance their line and our production line. The Norwegian National Library in Mo and Aarhus Statsbibliotek in Denmark will also be able to follow up our results.

\section{The process relies on high-quality microfilm}

The first step in the production line is the digitization of newspapers, from microfilm or from the original. Newspapers have been a main target for the reformatting program in Finland, Sweden, Norway and Denmark since 1950s. This makes it possible to use microfilm as intermediary for digitization if the film quality is high enough.

The process of digitizing newspapers includes microfilming, digitization and OCR, identification and database import. The newspapers are refilmed if the quality of the present microfilms is not good enough. Digitization means scanning the microfilms in black and white or in grayscale. OCR is the conversion of the images to text files and it requires many adjustments and training of the software. Identification of the title, issue, date, pages and attachments requires some human treatment. Database import is carried out by a separate software.

"Guidance on the best practice for microfilming of newspapers in preparation for possible future digitisation" is available in English, French, Spanish and Chinese on the International Federation of Library Associations and Institutions-net. ${ }^{8}$ The Guidance is based on the information gathered within the TIDEN project. Information is also available on the TIDEN website at http://tiden.se.

\section{Better service for the users}

Our goals in Helsinki University Library National Library of Finland are to obtain an industrial production environment, an automated OCR of both Fraktur and Roman text even within a page, the highest possible quality, highlighting of search words on the newspaper page, cost-effectiveness, the high speed of the process and the xml-METS-standard (developed by Library of Congress, USA).

The results of the OCR conversion in Finland and Sweden have shown that there are several factors influencing the quality of the conversion, the most important of them being the text font, language and reduction rate. From the very start of the TIDEN project it was obvious that a 100 per cent OCR conversion is impossible. Owing to the old language and the great mass of text, proofreading was not our way to enhanced search. It was thus decided that the ASCII versions of the text would be used for searching purposes only. The basic tool for the users was the digital facsimile of the original pages. A retrieval ware with fuzzy search possibilities was chosen in Sweden and Finland to identify the search words even if one to three letters would differ from the word sought for. The search tool processes the words as bit-strings and uses pattern recognition to find matches.

The speed and automation of the production environment is essential when comparing the process from 5-8 years ago to the possibilities today. The automated processes offer the coordinates to each word in the paper. Thus, users get better service as the words are highlighted. Other improvements are available. Images are of a better quality as the microfilm 
scanners and the OCR software are able to handle grayscale images automatically. Previously, Roman text had to be especially trained for the OCR software. Now we are looking at a breakthrough where the text is interpreted automatically.

There are interesting vendors offering reasonable production automation environments on the market. Helsinki University Library and the Royal Library of Sweden tested one of them in 2004. The test period gave us very good information about the key issues for the new production line when carrying out a request for tenders.

If a suitable production environment could be established, it could be used for other digitized collections as well.

\section{CONNECTING THE PAST}

In digital futures, the digital collection management will be an exciting challenge. It is not enough to digitize our cultural heritage collections and put them on the web with enhanced search possibilities. The infrastructure around the collections is changing fast as well as the expectations of the users. We have to improve access in various ways, including automatic translation to our old holdings and meeting places for users. We have to connect the users to each other, to holdings in other heritage sectors and so on. We do have to make the decisions on the roles of libraries. We have to decide which services are free and which are not.
Today, the Historical Newspaper Library in Finland has found its place. It is highly regarded among researchers, especially in the field of history and languages. It has also found its way to the public at large via information in the media and from person to person. Many a person is doing some genealogy from home with the help of the newspaper library. Finnish immigrants are using the library, finding information on their families leaving Finland and following them to their new country. Last year, 150,000 visits were recorded and 1.8 million pages were searched for. Still, we have to extend the use to education in schools.

People are very enthusiastic about the Finnish online newspaper library. It is easy to use in its Google-like approach. The users still want more and we will try to meet their needs. One future aim has been to coordinate a search to the Nordic historical digital newspaper library. Perhaps also that could be a new challenge for the future.

\section{References and Notes}

1 www.sanomalehdet.fi/en/tietoa/index.html, p. 2.

2 www.sanomalehdet.fi/en/tietoa/index.html, p. 3.

3 Hufvudstadsbladet. (2005) April;. www. sanomalehdet/en/tietoa/index.fi, p. 3.

4 www.sanomalehdet.fi/suomenlehdistö/fi.

5 www.sanomalehdet/en/tietoa/index.shtml, p. 4.

6 The Waterloo Directory of Scottish Newspapers and Periodicals 1800-1900. North Waterloo Academic Press, Waterloo, ON, 1989.

7 http://tiden.kb.se.

8 www.ifla.org. 